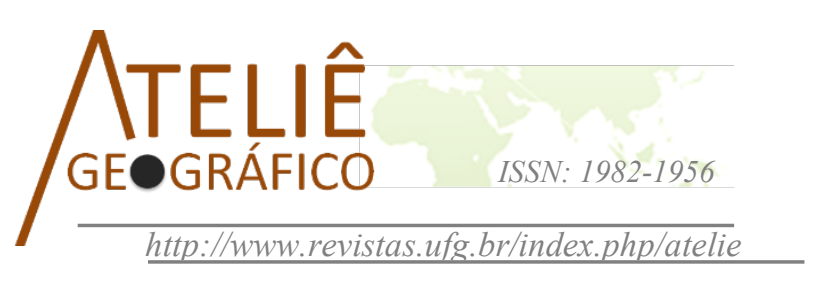

\title{
Mapeamento geoparticipativo: caminhos para a construção da gestão participativa das águas em tempos de crise hídrica a partir da metodologia $3 P$
}

\author{
Geoparticipatory mapping: approaches for establishing \\ participatory water management in times of water crisis \\ using the $3 P$ methodology
}

Cartographie géoparticipatoire: approches pour établir une gestion participative de l'eau en période de crise en utilisant la méthodologie $3 P$

\author{
Lussandra Gianasi \\ Universidade Federal de Minas Gerais \\ lussandrams@gmail.com \\ Daniela Campolina \\ Universidade Federal de Minas Gerais \\ danicampolina@gmail.com
}

\begin{abstract}
Resumo
No contexto de "Crise Hídrica", há de se perguntar: qual o papel da educação geográfica nesse tópico? As ações humanas influenciaram decisivamente a ocorrência de fatores que resultam na "Crise". Contraditoriamente, a própria não ação também contribuiu para ela. Como? A alienação e a falta de processos participativos nas escolas, envolvendo desde a consciência do dinamismo formativo dos territórios e a implicação das pessoas na tomada de decisões sobre a gestão de territórios - e das águas - são consideradas "não-ação". Dessa forma, a imobilidade pedagógica também contribui para esse quadro. Nesse sentido, apresentamos uma metodologia para tratar das questões voltadas à discussão e à análise de bacias hidrográficas por um conjunto de práticas educativas geográficas: $3 \mathrm{P}$ reconhecer $\mathrm{o}$ Problema (1P), observar a Potencialidade (2P) e ver a Possibilidade (3P) desenvolvida na extensão. Como resultados, analisamos a Microbacia Hidrográfica do Córrego João Gomes Cardoso em Contagem-MG e questões desafiadoras para as ações ligadas aos tempos de aplicação, infraestrutura e defasagem de conhecimento geográfico e tecnológico. Observamos que o $3 \mathrm{P}$ tem potencial pedagógico no ensino da Geografia, podendo não apenas auxiliar no entendimento da espacialidade e da dinâmica do território hidrográfico, mas na construção crítica sobre suas transformações.
\end{abstract}

Palavras-chave: Mapeamento geoparticipativo 3P, gestão das águas, geografia. 


\begin{abstract}
In a context of "water crisis", one must ask: what is the role of geographic education regarding this subject matter? On the one hand, human actions have decisively influenced the incidence of factors that result in the "Crisis". On the other hand, contradictorily, nonactions have also contributed in leading to it. How? "Non-actions" comprise estrangement and lack of participatory processes within schools, from the consciousness about the dynamism of territories - encompassing waters - to the involvement of people in territory management decision-making. Pedagogical immobility, thus, contributes to this scenario. In this sense, we present a methodology to address issues related to the discussion and analysis of drainage basins by means of a set of geographic educational practices: 3P: recognize Problem (1P), observe Potentiality (2P) and see Possibility (3P). As a result, we analyze challenging issues related to the time of application, infrastructure, and the gap between geographic and technological knowledge. 3P has educational potential, not only for aiding in the understanding of spatiality and the dynamics of the hydrographic territory, but also in building a critical view of its transformations.
\end{abstract}

Keywords: Geoparticipatory mapping 3P, Geography, water management.

\begin{abstract}
Résumé
Dans le contexte de la « crise de l'eau », il faut se demander : quel est le rôle de l'éducation géographique en ce qui concerne ce sujet ? Les actions humaines ont décisivement influencées l'incidence de facteurs générateurs de cette «crise», alors que les «nonactions » ont contribuées à l'éloignement et l'absence de processus participatifs au sein des écoles et communautés.

En ce sens, nous proposons une méthodologie visant à aborder les questions liées à la discussion et l'analyse des bassins versants au travers d'un ensemble de pratiques éducatives-géographiques: 3P: reconnait le problème (1P), observe le potentiel (2P) et voit la possibilité (3P). En s'appuyant sur des projets de recherche et d'extension universitaire auprès des communautés concernées, nous analysons les enjeux associés à la mise en oeuvre de cette méthodologie.

Nous notons que le $3 \mathrm{P}$ a un potentiel éducatif dans l'enseignement de la Géographie, non seulement pour aider à la compréhension de la spatialité et de la dynamique du territoire hydrographique, mais aussi dans la construction d'une vision critique de ses transformations historiques.

Mots clés: Cartographie géoparticipatoire 3P, crise de l'eau, gestion de l'eau, géographie.
\end{abstract}

\title{
Introdução
}

Em meio a um contexto de "Crise Hídrica" que assola o Brasil, sendo que em algumas regiões com mais intensidade, há de se perguntar: qual o papel da educação geográfica em meio a esse contexto? Para além das rasas informações que são jogadas de maneira dispersa e fragmentada pelos meios de comunicação em massa, há uma realidade que se configurou ao longo de vários anos, envolvendo uma complexa gama de fatores que desencadearam hoje a chamada "Crise Hídrica". As ações humanas influenciaram decisivamente a ocorrência de fatores que resultaram na "Crise". Contraditoriamente a própria não-ação também contribuiu para a "Crise". Como? A alienação e falta de processos participativos envolvendo desde a consciência do dinamismo formativo dos territórios até o envolvimento de atores diversos na tomada de decisões sobre a gestão de territórios, e, consequentemente da gestão das águas, ou seja, 
pode-se considerar que a "não-ação", a imobilidade, também contribui para um quadro de "Crise Hídrica".

Essa "Crise" pode inicialmente parecer contraditória se considerarmos o Brasil como uma potência hídrica por possuir $12 \%$ do total de água doce disponível do planeta; $90 \%$ dos seus rios serem perenes; abrigar vários aquíferos - dentre eles o Guarani 1; ter $90 \%$ do seu território recebendo chuvas constantes e com variáveis níveis de precipitação, além de contar com grandes extensões de importantes áreas úmidas do planeta como o Pantanal e Amazônia; e ainda a maior bacia hidrográfica do mundo localizar-se boa parte no território brasileiro - a bacia hidrográfica do rio Amazonas (REBOUÇAS, 2001).

Mas, a disponibilidade hídrica não é distribuída igualmente no território brasileiro. Convivemos com situações de abundância e escassez. Mesmo em meio à grande quantidade de água, em algumas regiões o mau uso do solo e da água faz com que não possamos usufruir desse recurso. Diante dessa realidade retomamos balizados nos Parâmetros Curriculares Nacionais (PCN) a pergunta inicial:

"Qual o papel da educação geográfica em meio a esse contexto?” A educação escolar brasileira tem contribuído para a formação de jovens capazes de "posicionar-se de maneira crítica, responsável e construtiva nas diferentes situações sociais, utilizando o diálogo como forma de mediar conflitos e de tomar decisões coletivas"? (BRASIL, 1998).

O presente artigo não objetiva responder ou discorrer profundamente sobre tais perguntas. Pretende estimular a reflexão e questionamento quanto às possibilidades da educação brasileira, e, mais especificamente da educação geográfica, não apenas na contribuição quanto ao entendimento dos fatores que levaram a "crise hídrica", mas também quanto ao potencial (ou não) de processos educativos que possam realmente auxiliam na formação de sujeitos que se posicionem "de maneira crítica, responsável e construtiva" e que sejam aptos a tomarem decisões que possam influenciar na gestão dos territórios e, consequentemente, das águas.

Em relação aos PCNs de Geografia Kaercher (1997) afirma que apesar de sedutor, o documento apresenta-se distante da realidade vivenciada nas escolas. Souza (2011, p.59) afirma que nas últimas décadas as pesquisas e a literatura na área da educação geográfica "apresentam consideráveis avanços nas propostas de ensino de Geografia, relacionadas aos aspectos da formação e da espacialidade geográfica." Autores como Cavalcanti (1998, 2002), Callai (2000), Straforini (2004), Castellar (2005) tem discorrido sobre a importância da educação geográfica na formação do raciocínio geográfico objetivando a formação de sujeitos críticos e participativos. Além disso, os autores citados têm apresentado e discutido conceitos, práticas e metodologias de ensino, estruturantes do pensamento espacial para uma formação cidadã. E, em eventos da

\footnotetext{
${ }^{1} \mathrm{O}$ aquífero Guarani é considerado o maior do mundo com 1,2 milhões de $\mathrm{Km}^{2}$, com um volume estimado em $370.000 \mathrm{Km}^{3}$; sendo que $70 \%$ da sua área se localiza em território brasileiro (RIBEIRO, 2009).
} 
Geografia, mais especificamente dos Encontros Nacionais de Práticas de Ensino ENPEGs e dos Encontros Nacionais de Ensino de Geografia - é possível identificar a existência de práticas referentes ao ensino da disciplina que evidenciam mudanças na Geografia ensinada nas escolas o que aponta, segundo Souza (2011, p.59), para "perspectivas animadoras referentes às mudanças desejadas no ensino da disciplina".

Mas, apesar destes esforços acadêmicos e do desenvolvimento de metodologias e práticas que objetivam transpor a Geografia tradicional ainda ensinada nas escolas, é consenso entre esses autores que estamos longe de afirmar que no Brasil há ensino, de forma generalizada, de uma Geografia que realmente contribua significantemente para uma formação cidadã, na qual os estudantes participem ativamente de decisões que interfiram na gestão de território, assim como na gestão das águas. Quanto à importância da Geografia escolar na formação cidadã tomamos como referência Cavalcanti (2002; 2006, p. 34) que diz:

\begin{abstract}
Cabe reafirmar e explicitar a importância da Geografia escolar para a formação geral de cidadãos. Na relação cognitiva de crianças, jovens e adultos com o mundo, o raciocínio espacial é necessário, pois as práticas sociais cotidianas têm uma dimensão espacial. Os alunos que estudam essa disciplina já possuem conhecimentos nessa área oriundos de sua relação direta e cotidiana com o espaço vivido. Sendo assim, o trabalho de educação geográfica é o de ajudar os alunos a analisarem esses conhecimentos, a desenvolverem modos do pensamento geográfico, a internalizarem métodos e procedimentos, de captar a realidade vivida e "apresentada" pela geografia escolar, tendo consciência de sua espacialidade. Esse modo de pensar geográfico é importante para a realização de práticas sociais variadas, já que essas práticas são sempre práticas socioespaciais.
\end{abstract}

Dentre as "práticas socioespaciais" existentes considera-se aqui a gestão participativa das águas. Acreditamos que a defasagem do ensino em Geografia contribui para o não entendimento do espaço vivido, assim como as relações complexas que envolvem uma gestão das águas que favoreça a qualidade e quantidade de água para os diversos usos.

Favorecendo essa gestão participativa das águas, em 1997, o Brasil instituiu a Política Nacional de Recursos Hídricos através da Lei 9.433/97 (BRASIL, 1997), que ficou conhecida como "Lei das Águas". Segundo esta, "a gestão dos recursos hídricos deve ser descentralizada e contar com a participação do poder público, dos usuários ${ }^{2}$ e das comunidades" e, ser exercida por órgãos colegiados, os chamados comitês de bacia

\footnotetext{
2 "Usuários ou usuário de água - termo usado na gestão de recursos hídricos para designar todos aqueles que utilizam diretamente as águas superficiais ou subterrâneas de uma bacia hidrográfica. Pode ser pessoa física ou jurídica, de direito privado ou público e que independente da necessidade de outorga prevista nos termos da lei, faz uso dos recursos hídricos, captando água diretamente de cisternas, açudes, córregos, rios lagos ou que faz qualquer lançamento de efluentes (esgotos industriais, agrícolas ou domésticos) diretamente nos corpos d'água" (MACHADO et al., 2011, p. 98).
} 
hidrográfica $(\mathrm{CBH})$. Estes são espaços de discussão e decisão sobre os usos da água, além de planejamento de ações para a manutenção da qualidade e quantidade desse recurso. O território de gestão dos comitês constitui-se de bacias hidrográficas, as quais de acordo com a lei devem ser "unidades básicas de planejamento do uso, da conservação e da recuperação dos recursos naturais" (BRASIL, 1997). Mas, apesar da lei ser instituída em 1997, o sistema de gestão dos recursos hídricos ainda não foi totalmente implantado no Brasil e ainda chega lentamente nas escolas com projetos estruturantes sobre o assunto.

A Lei das Águas representou um avanço legal no sentido instituir uma proposta de gestão democrática das águas, porém, após quase 20 anos de sua promulgação podese perceber que o Sistema Nacional de Gerenciamento de Recursos Hídricos não tem funcionado como previsto. E a gestão, que deveria ser democrática, tem se mostrado tecnocrática como afirma Abers (2010) ao realizar estudos sobre os CBHs, os conselhos previstos como gestores das águas. De acordo com a autora, a voz das comunidades, da sociedade civil tem sido abafada pelos representantes do poder público e usuários que imbuídos de conhecimentos técnico-científicos teimam em deslegitimar os conhecimentos das comunidades sobre o lugar em que vivem. Os conhecimentos científicos e técnicos são importantes nos processos de gestão, mas, nos CBHs os conhecimentos que deveriam auxiliar nos processos de tomada de decisões, tem sido um impasse na legitimação da gestão participativa e descentralizada, já que o acesso a estes conhecimentos ocorre de forma desigual, podendo ser manipulados a favor de interesses específicos (ABERS, 2010; CARMO et al., 2012; CAMPOLINA, 2014; JÚNIOR \& FIDELMAN, 2009; LEMOS et.al. 2010).

Diante do contexto apresentado pergunta-se: como a escola tem se posicionado na questão da gestão das águas? E a educação geográfica e política? Se tantos são os anseios registrados em documentos de referência da educação brasileira, produções acadêmicas, até projetos de educação ambiental (desenvolvidos tanto por empresas, ONGs quanto setores públicos) sobre formação de "sujeitos críticos" e aptos a tomarem decisões, estamos nesse caminho? Perguntamos: como estas instâncias educativas têm contribuído para a construção de uma gestão realmente participativa das águas com sujeitos críticos?

Esforços têm surgido pelo Brasil, principalmente na vertente de educação ambiental como pode ser constatado em experiências relatadas em publicações como "Política de Águas e Educação Ambiental: processos dialógicos e formativos em planejamento e gestão de recursos hídricos" do Ministério do Meio Ambiente (BRASIL, 2013). Mas, em meio à crise hídrica, é preciso destacar o potencial da educação geográfica em trabalhar desde as configurações territoriais até as dinâmicas de formação do espaço de diversas maneiras dentre elas podemos destacar: o trabalho de campo com os alunos que nos apresenta seu espaço vivido e/ou com o professor estimulando novas (re)leituras desse espaço; pelo o uso de geotecnologias como o Google Earth para o mapeamento dessas realidades pelas cartografias sociais (ACSELRAD, 2010). Não seria 
exagero afirmar que a Geografia escolar é essencial na formação cidadã, e, por que não, na gestão participativa das águas.

Longe de querermos construir, mais uma discussão meramente teórica, sobre a relação entre a Geografia escolar e a gestão participativa das águas, pretende-se aqui apresentar um relato de experiência: uma tentativa de conectar saberes escolares com saberes dos alunos e professores quanto ao espaço vivido - tendo bacias hidrográficas como território de referência - em uma proposta educativa de construção de gestão local participativa das águas.

O presente trabalho remete há um percurso metodológico, reflexivo e participativo de cinco anos, que perpassou por programas e projetos de extensão que tiveram, como território de atuação, diferentes sub e microbacias integrantes da Bacia Hidrográfica do rio das Velhas (GIANASI et al., 2014) localizada na região central de Minas Gerais, umas urbanas e outras rurais. No entanto, apesar da reflexão com um histórico maior de atuação, apresentaremos a metodologia do último projeto de extensão financiado pelo Proext MEC SESu de 2014.

\section{Por que mapeamento geoparticipativo?}

As ações relacionadas ao mapeamento geoparticipativo se deram em três momentos, sendo o primeiro um programa de extensão financiado pelo MEC, o segundo, ocorrendo concomitante ao primeiro, o programa de popularização da ciência financiado pela FAPEMIG e o último um projeto de extensão financiado também pelo $\mathrm{MEC}^{3}$. Nesse artigo discutiremos e apresentaremos o último e finalizado, em meados de 2015, chamado: Projeto "Mapeamento e monitoramento geoparticipativo de microbacias hidrográficas ${ }^{4}$ ".

A escolha da microbacia de estudo no Projeto se deu pela influência de trabalhos anteriores (Editais MEC e FAPEMIG) desenvolvidos pelo Manuelzão Comunidade/ Proj. Manuelzão junto subcomitês de bacias, faculdades, escolas e Núcleos Manuelzão, dentre os quais o Núcleo João Gomes Cardoso - atuante no território da microbacia do Córrego do João Gomes Cardoso ${ }^{5}$ - mostrou destaque, por dar continuidade ao mapeamento criando um grupo de jovens que designaram de "Guardiões do Meio Ambiente". Esse grupo que recebeu formação do Núcleo Manuelzão João Gomes Cardoso, tinha o objetivo de monitorar as áreas mapeadas durante os projetos de extensão os quais desenvolveram a metodologia do mapeamento geoparticipativo. A atuação do Núcleo João Gomes Cardoso e a influência dos projetos de extensão com a metodologia do mapeamento geoparticipativo nas ações do grupo foram temas da

\footnotetext{
${ }^{3}$ Financiado pela FAPEMIG: "Capacitação de professores, produção e divulgação de conhecimentos sobre microbacias urbanas da bacia do rio das Velhas como instrumento de gestão participativa do ambiente" (20112013) e Programa Proext 2010, edital 5 "Ambiente, educação, saúde e cidadania para as microbacias urbanas e bacias do rio das Velhas" (2011-2012)

${ }^{4}$ Financiado pelo edital PROEXT-MEC SESu 2014 e realizado de janeiro de 2014 a julho de 2015.

${ }^{5} \mathrm{http}$ //www.manuelzao.ufmg.br/mobilizacao/nucleos/n\%C3\%BAcleo-jo\%C3\%A3o-gomes
} 
dissertação de mestrado Educação Ambiental na estruturação de Mundos Possíveis (CAMPOLINA, 2014): o caso do Núcleo João Gomes Cardoso/MG.

\section{Descrições da área}

A Bacia Hidrográfica de estudo, a Microbacia do Córrego João Gomes (FIG.1) tem $5,15 \mathrm{~km}^{2}$ de área e se localiza na região leste de Contagem na Regional Ressaca que se encontra na divisa entre os municípios de Contagem e Belo Horizonte. Tal localidade tem proximidade com importantes vias de acesso como a BR-040 que liga Belo Horizonte à Brasília e a Avenida Severino Ballesteros Rodrigues, uma via de acesso rápido que liga os municípios de Contagem à Belo Horizonte. Também se situa próximo aos grandes empreendimentos comerciais e industriais como a Central de abastecimento de Minas Gerais - CEASAMINAS, Shopping Contagem e o centro industrial de Contagem. Esta área limítrofe entre municípios se torna fator importante de discussão de bacia hidrográfica e divisão municipal, uma vez que faz divisa com áreas da capital mineira como a região da Pampulha e seu complexo arquitetônico que é Patrimônio da Humanidade pela UNESCO desde 2016 (à jusante).
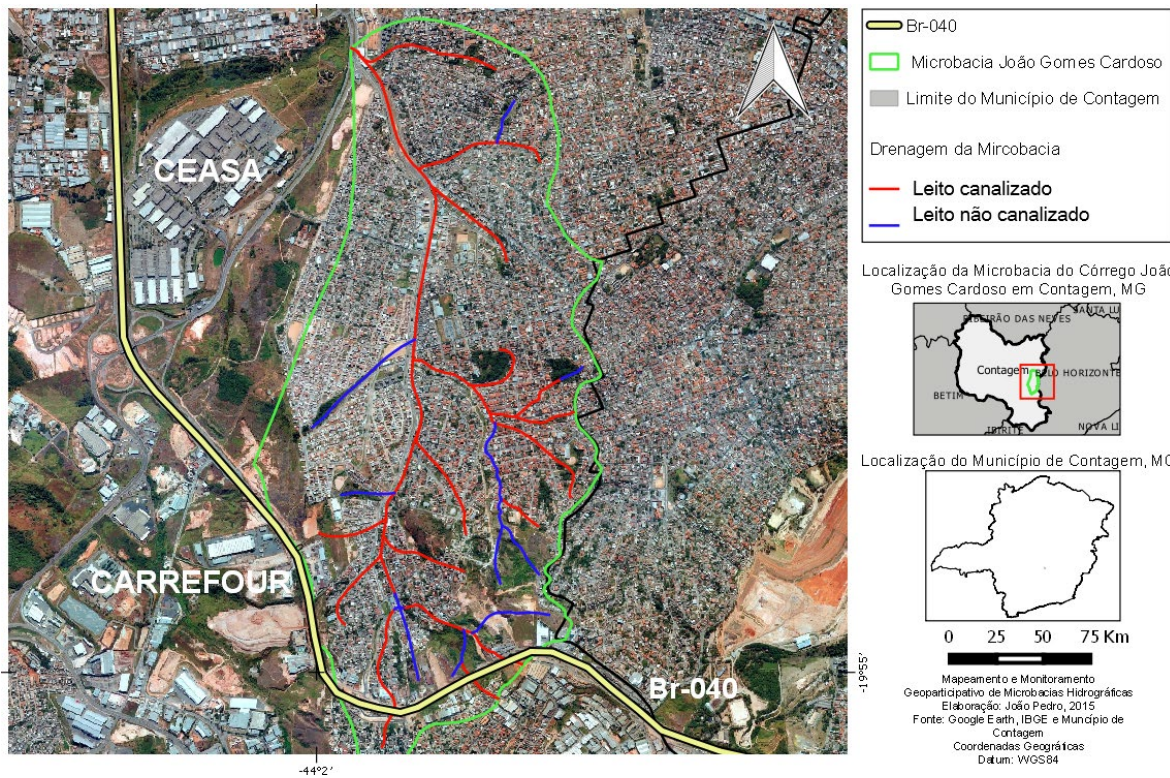

Localização da Microbacia do Córrego Joẫo Gomes Cardoso em Contagem, MG

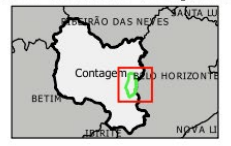

Localização do Município de Contagem, MG

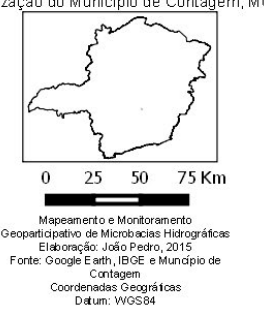

Figura 01: Localização da Microbacia Hidrográfica do Córrego do João Gomes Cardoso, Contagem-MG.

Fonte: Google Earth, IBGE e Município de Contagem, 2015.

Nesse território as áreas de nascentes, matas residuais, encostas e planícies fluviais ao longo de cursos d'água foram ocupadas. Parte do córrego principal e seus 
afluentes foram canalizados, sendo uns invisíveis e de forma fechada situando-se sob avenidas e praças, outros abertos evidenciando sua poluição.

\section{Metodologia}

O projeto de Mapeamento Geoparticipativo de Microbacias Hidrográficas é sustentado pelo arcabouço teórico, denominado de metodologia "3P", que é definida como: reconhecer os (1P) Problemas existentes, observar e indicar as (2P) Potencialidades e levantar as (3P) Possibilidades de realização de ações que podem ser efetivadas para o local (GIANASI et al, 2016; VIEIRA, et al. 2011, 2012 e 2013). O Quadro 01 apresenta exemplos de resultados encontrados nos trabalhos de campo e análises de imagens de satélite.

Quadro: 01: Resultados diversos obtidos pela técnica 3P nos Núcleos de bacias Manuelzão.

\begin{tabular}{|c|c|c|}
\hline \multirow[b]{2}{*}{ PROBLEMAS (1P) } & \multirow{2}{*}{ POTENCIALIDADE (2P) } & \multirow{2}{*}{ POSSIBILIDADE (3P) } \\
\hline & & \\
\hline $\begin{array}{l}\text { Ausência de áreas verdes; } \\
\text { desmatamento; presença de } \\
\text { áreas verdes degradadas }\end{array}$ & Áreas verdes existentes & $\begin{array}{l}\text { Plantio de mudas e revitalização de } \\
\text { áreas verdes, proteção de matas } \\
\text { nativas }\end{array}$ \\
\hline Nascentes degradadas & Nascentes presentes & $\begin{array}{l}\text { Registro de nascentes existentes, } \\
\text { realizar campanhas de proteção e } \\
\text { revitalização de nascentes }\end{array}$ \\
\hline $\begin{array}{l}\text { Lançamento de esgotos e } \\
\text { efluentes industriais in natura }\end{array}$ & $\begin{array}{l}\text { Cursos de água preservados em } \\
\text { leito natural existentes }\end{array}$ & $\begin{array}{l}\text { Implantar a coleta e interceptação e } \\
\text { tratamento do esgoto mobilizando o } \\
\text { poder público, associações de bairro } \\
\text { e núcleos Manuelzão }\end{array}$ \\
\hline $\begin{array}{l}\text { Cursos d'água em leito natural } \\
\text { sem canalização com ausência } \\
\text { de vegetação nativa, córregos } \\
\text { canalizados e tampados por } \\
\text { avenidas }\end{array}$ & $\begin{array}{l}\text { Cursos de água em leito natural } \\
\text { com vegetação nativa }\end{array}$ & $\begin{array}{l}\text { Realizar campanhas para manter os } \\
\text { cursos d'água em leito natural com } \\
\text { vegetação nativa nas margens, } \\
\text { promover plantios de espécies } \\
\text { nativas nas margens, promover } \\
\text { campanhas de conscientização sobre } \\
\text { a não canalização dos córregos }\end{array}$ \\
\hline $\begin{array}{l}\text { Córrego poluído, presença de } \\
\text { lixo e esgoto, vetores de } \\
\text { transmissão de doenças, } \\
\text { registros de casos de dengue e } \\
\text { doenças de veiculação hídrica }\end{array}$ & Ecossistema saudável presente & $\begin{array}{l}\text { Mobilizar a comunidade e a unidade } \\
\text { de saúde informando-os e } \\
\text { conscientizando-os sobre as } \\
\text { consequências do comprometimento } \\
\text { do ecossistema para a saúde coletiva }\end{array}$ \\
\hline $\begin{array}{l}\text { Disposição inadequada de } \\
\text { resíduos sólidos (lixo) a céu } \\
\text { aberto e/ou em cursos d'água }\end{array}$ & Destino adequado do lixo & $\begin{array}{l}\text { Realizar ações de educação e } \\
\text { conscientização ambiental sobre o } \\
\text { destino correto do lixo e dos } \\
\text { maleficios para a saúde coletiva, } \\
\text { promover o reaproveitamento de } \\
\text { materiais recicláveis, o consumo } \\
\text { sustentável, a coleta seletiva e a } \\
\text { implantação de usina de lixo }\end{array}$ \\
\hline $\begin{array}{l}\text { Áreas desmatadas e com } \\
\text { possibilidade de erosão, } \\
\text { deslizamentos e assoreamentos } \\
\text { diversos }\end{array}$ & Solo protegido visível & $\begin{array}{l}\text { Intervenções nas áreas visando sua } \\
\text { recuperação com plantio de espécies } \\
\text { nativas, para conter erosão, evitando } \\
\text { deslizamento }\end{array}$ \\
\hline
\end{tabular}




\begin{tabular}{|c|c|c|}
\hline PROBLEMAS (1P) & POTENCIALIDADE (2P) & POSSIBILIDADE (3P) \\
\hline $\begin{array}{l}\text { Escassez ou ausência de peixes } \\
\text { e outras espécies aquáticas }\end{array}$ & Biodiversidade aquática & $\begin{array}{l}\text { Diagnosticar os fatores responsáveis } \\
\text { pela poluição da água que } \\
\text { comprometem a existência da } \\
\begin{array}{l}\text { biodiversidade, promover ações de } \\
\text { revitalização pela volta da } \\
\text { biodiversidade }\end{array}\end{array}$ \\
\hline $\begin{array}{l}\text { Águas poluídas perceptíveis } \\
\text { por aspectos (cor, mau cheiro, } \\
\text { turbidez, espuma, materiais } \\
\text { flutuantes) }\end{array}$ & $\begin{array}{l}\text { Qualidade das águas dos corpos } \\
\text { d'água perceptível aos olhos }\end{array}$ & $\begin{array}{l}\text { Conseguir análise da água e verificar } \\
\text { o tipo de poluição existente, } \\
\text { pesquisar as possíveis fontes de } \\
\text { poluição, e mobilizar a sociedade, o } \\
\text { poder público e usuários para } \\
\text { melhorar a qualidade das águas, } \\
\text { comunicar situações ao subcomitê de } \\
\text { bacias atuante na região }\end{array}$ \\
\hline $\begin{array}{l}\text { Falta de informação e } \\
\text { mobilização em prol de } \\
\text { questões socioambientais }\end{array}$ & Mobilização socioambiental & $\begin{array}{l}\text { Realizar travessias na bacia com } \\
\text { moradores no intuito de conscientizá- } \\
\text { los sobre os problemas (1P) e } \\
\text { potencialidades (2P) da bacia, } \\
\text { realizar palestra nas escolas, } \\
\text { associações de bairro com intuito de } \\
\text { mobilizar pessoas em prol de } \\
\text { melhorias locais, elaborar blogs e } \\
\text { utilizar redes sociais diversas para } \\
\text { divulgar informações sobre a região e } \\
\text { fazer mapas on line pelas plataformas } \\
\text { digitais e divulgar os links nas } \\
\text { escolas, etc }\end{array}$ \\
\hline
\end{tabular}

Fonte: Resultados de aplicação da Metodologia nos Núcleos Manuelzão6.

A metodologia citada é utilizada para reconhecer o território a partir do mapeamento geoparticipativo, sendo este realizado em ações conjuntas entre os técnicos/pesquisadores e comunidades, buscando uma solidariedade entre os atores sociais. Este tipo de técnica cartográfica dialoga em nosso projeto com a educação ambiental, uma vez que, busca-se o discernimento dos indivíduos quanto à problemática envolvendo o ambiente e o modo de vida social que pode ser, por exemplo, da implantação da metodologia 3P na FIG. 02.

\footnotetext{
6 https://manuelzao.ufmg.br/nucleos/. Essa sistematização de resultados ocorreu em vários núcleos de diferentes bacias hidrográficas de Belo Horizonte onde a metodologia foi aplicada.
} 


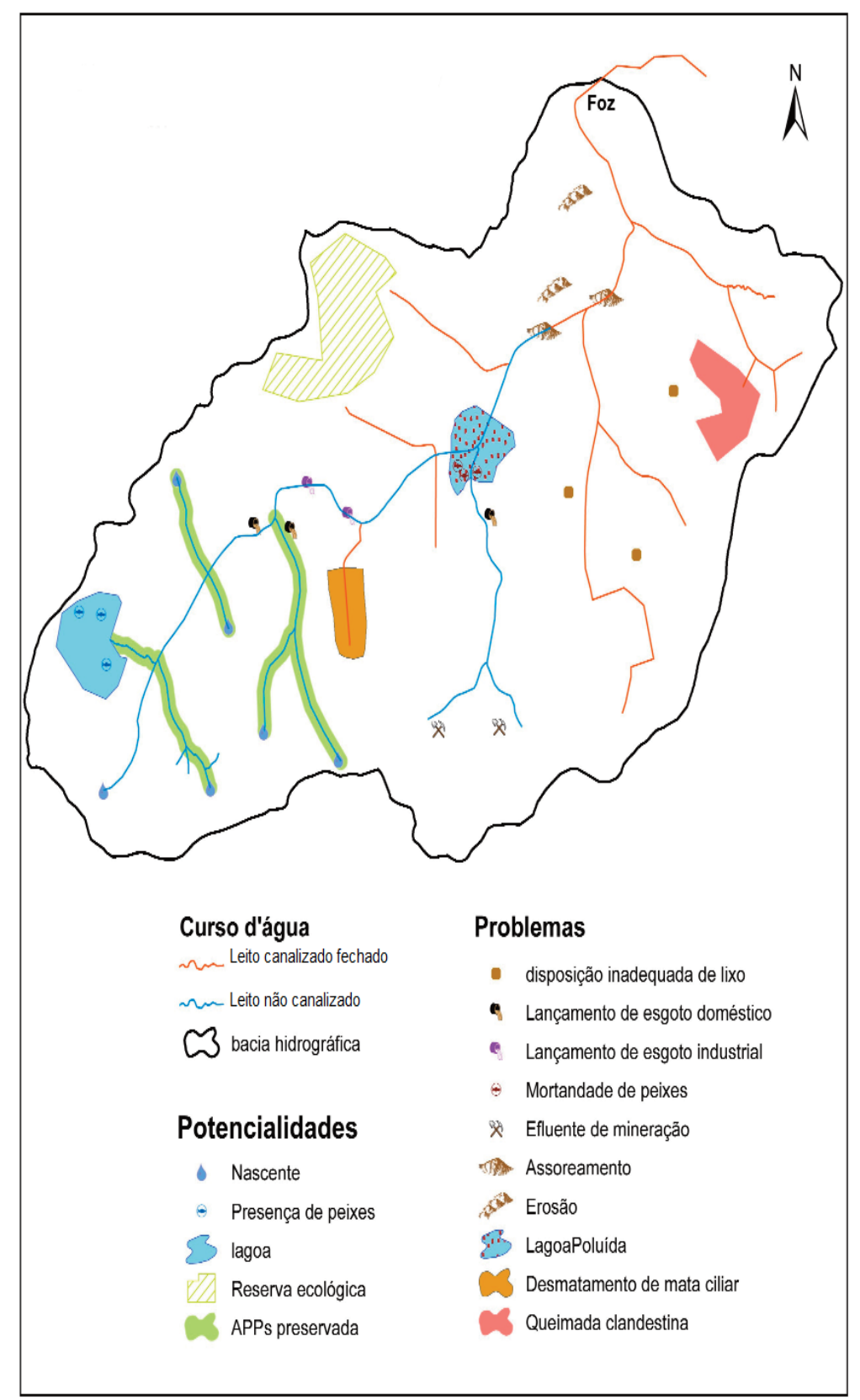

Figura 02: Modelos de Mapeamento Participativo Possíveis

Fonte: Vieira et al., 2011 
Dentro das temáticas, optou-se em trabalhar com bacia hidrográfica, pois esta não leva em consideração o caráter da divisão política do território, a partir disso podemos pensar em novas formas de organização do espaço que interferem na dinâmica das águas. Exemplos efetivos e concluídos desse mapeamento geoparticipativo são apresentados nas FIG. 03 e 04 da microbacia Hidrográfica do córrego do João Gomes.

As figuras 03 e 04 demonstram o avanço em relação ao entendimento sobre a bacia pela comunidade e apresenta os aspectos a partir da metodologia $3 \mathrm{P}$ que eles observaram e analisaram e, portanto, foi mapeado a partir da ferramenta Google Earth.

O reconhecimento dos Problemas (1P) é feito basicamente pelo trabalho de campo, pela oficina de mapa mental, pela maquete e via Google Earth. Segundo Claudino (2018) "o trabalho de campo de Geografia deve estar ao serviço da construção da cidadania local"(...) ele "é o conjunto das atividades de aprendizagem que envolvem a recolha direta de informação, nos lugares e com as pessoas, depois complementadas pela análise, reflexão e comunicação dos resultados obtidos".
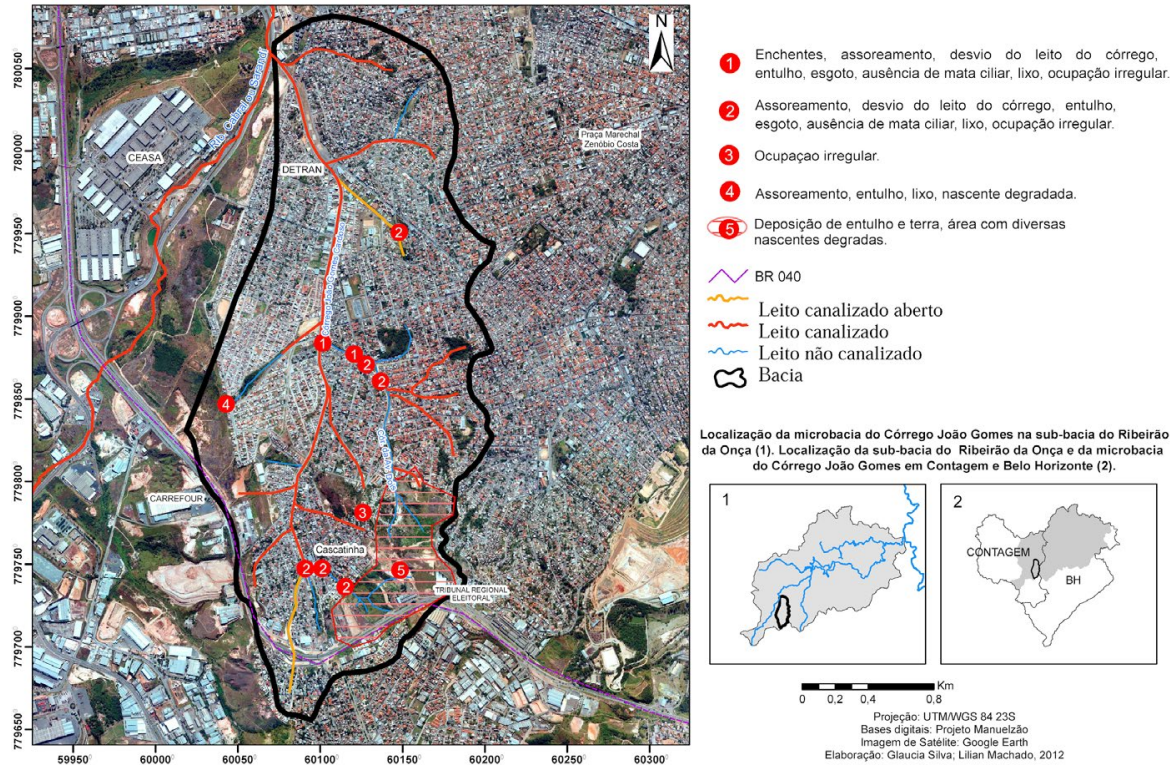

Localização da microbacia do Córrego Joăo Gomes na sub-bacia do Ribeirão da Onça (1). Localização da sub-bacia do Ribeirăo da Onça e da microbacia do Córrego Joăo Gomes em Contagem e Belo Horizonte (2).

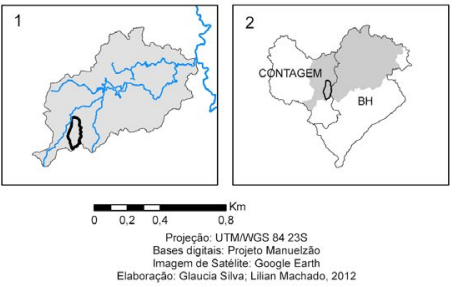

Figura 03: Problemas (1P) na microbacia João Gomes, Contagem - Minas Gerais 


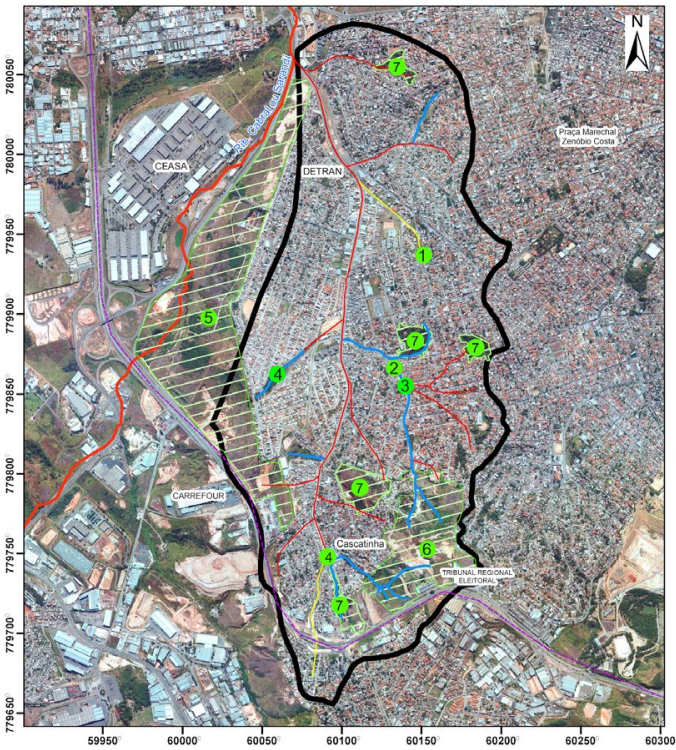

Figura 04: Potencialidades (2P) e Possibilidades

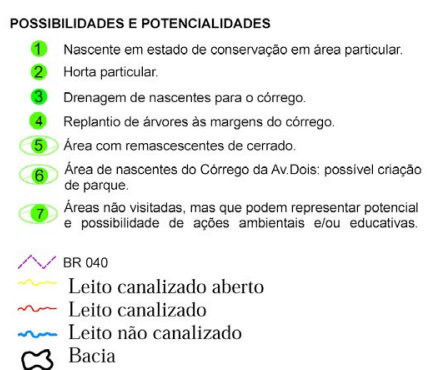

Localizaçăo da microbacia do Córrego Joăo Gomes na sub-bacia do Ribeirão da Onça (1). Localização da sub-bacia do Ribeirāodo Onça

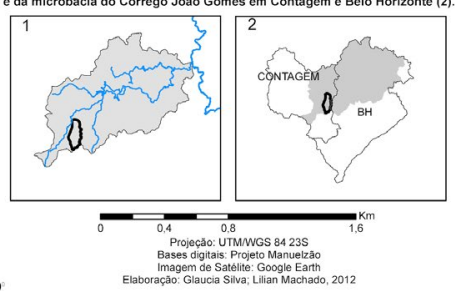

(3P) na microbacia João Gomes,

Contagem - Minas Gerais.

A etapa de diagnosticar os problemas é considerada a de menor dificuldade por quem aplica a metodologia, pois observar in loco o que nos afeta, muitas vezes ele já foi vivenciado pelos alunos em sua comunidade do entorno da escola, pois a maioria mora próximo. Portanto, mapear mentalmente, depois manualmente (maquete) e por final digitalmente torna-se uma prática educativa significativa e uma tarefa do cotidiano dos alunos que transforma o Problema (1P) em representação cartográfica de várias formas, papel, mente, mãos e mapa digital.

Já observar e indicar as Potencialidades (2P) e levantar ações possíveis por meio das Possibilidades (3P) é um exercício didático de maior trabalho e é produzido tanto na oficina de maquete quanto depois no mapeamento digital. Muitos dos alunos não exercem ou vislumbram Potencialidades (2P) e nem as Possibilidades (3P), pois o exercício da cidadania territorial ${ }^{7}$ (Claudino, 2014) ainda é uma prática muito pouco aplicada e necessita de um exercício de possibilitar criar novos mundos, por vezes está em um imaginário não desdobrado para a sua realidade, não mapeado. Muitas vezes os alunos se acham impossibilitados de exercer e de demandar isso aos órgãos públicos, aos conselhos, às associações de bairro e principalmente à sua mente aos seus atos. É nesse sentido que o projeto almeja tocar; tornar o aluno um ser territorial, que atua como

\footnotetext{
${ }^{7}$ Claudino (2014) explica que preferi o conceito de cidadania territorial ao de cidadania espacial, pois território está diretamente relacionado com a apropriação, transformação e identificação das comunidades com o território em que habitam.
} 
cidadão do seu território, que pode e deve modificar/mentalizar/agir no seu cotidiano espacial, que envolve o social, o ambiental e por que não o econômico?

Portanto, o caminho metodológico trilhado na execução do projeto Mapeamento Geoparticipativo de Microbacias Hidrográficas pelo 3P, é explicado nos itens de A a F, abaixo.

A - Captação das escolas a participarem do projeto

Escolas localizadas na microbacia do córrego João Gomes Cardoso e que já haviam participado de projetos de extensão anteriores desenvolvidos pelo Manuelzão Comunidade/Proj. Manuelzão foram visitadas pela equipe do projeto Mapeamento tendo o acompanhamento de um líder comunitário da região e participante do Núcleo Manuelzão João Gomes Cardoso. Três escolas aceitaram o pedido, sendo elas: Escola Municipal Maria Silva Lucas (CAIC-Laguna) com a qual trabalhou-se com uma turma do $6^{\circ}$ ano, Escola Municipal Padre Joaquim de Souza e Silva, com alunos de uma turma do $6^{\circ}$ ano ao $1^{\circ}$ ano do ensino médio e a Escola Estadual Professora Lígia Maria de Magalhães, com uma turma do $2^{\circ}$ ano do Ensino Médio;

B - Minicurso de capacitação para o mapeamento e monitoramento geoparticipativos

O minicurso ocorreu no Instituto de Geociências da UFMG e foi ministrado ${ }^{8}$ pelas professoras coordenadoras e bolsistas do projeto. No minicurso foram abordadas temáticas do campo da Geografia como o ciclo da água, ferramentas de geolocalização e conceitos da epistemologia geográfica como território, lugar, local, paisagem, espaço para que pudéssemos resgatá-las durante as oficinas futuras, readequando a didática da Geografia, dos conceitos e teoria para o grupo presente.

C - Trabalho de campo

Foi realizado um trabalho de campo com cada turma tendo por objetivo apresentar as questões ambientais, sociais mais proeminentes de pontos da microbacia do córrego João Gomes. Participaram alunos e professores das três escolas e foram conduzidos pela vice-coordenadora do projeto e os bolsistas participantes. Foram percorridos diversos pontos da microbacia do Córrego do João Gomes Cardoso como nascentes, partes do córrego em leito natural e com canalização tentando identificar as mudanças ocorridas a partir de registros dos projetos anteriores, registradas em fotos e mapas. Durante cada trabalho de campo discutiu-se sobre os motivos das mudanças ocorridas na paisagem e as consequências dessas mudanças dentro da dinâmica da bacia hidrográfica em questão.

\footnotetext{
${ }^{8}$ A equipe do projeto que ministrou o curso foi: 2 professoras coordenadoras: Lussandra e Daniela e três bolsistas alunos da graduação em geografia da UFMG (Rodrigo Cavalcante Silva, Guilherme de Oliveira Parreira e João Pedro dos Santos e outros alunos voluntários).
} 


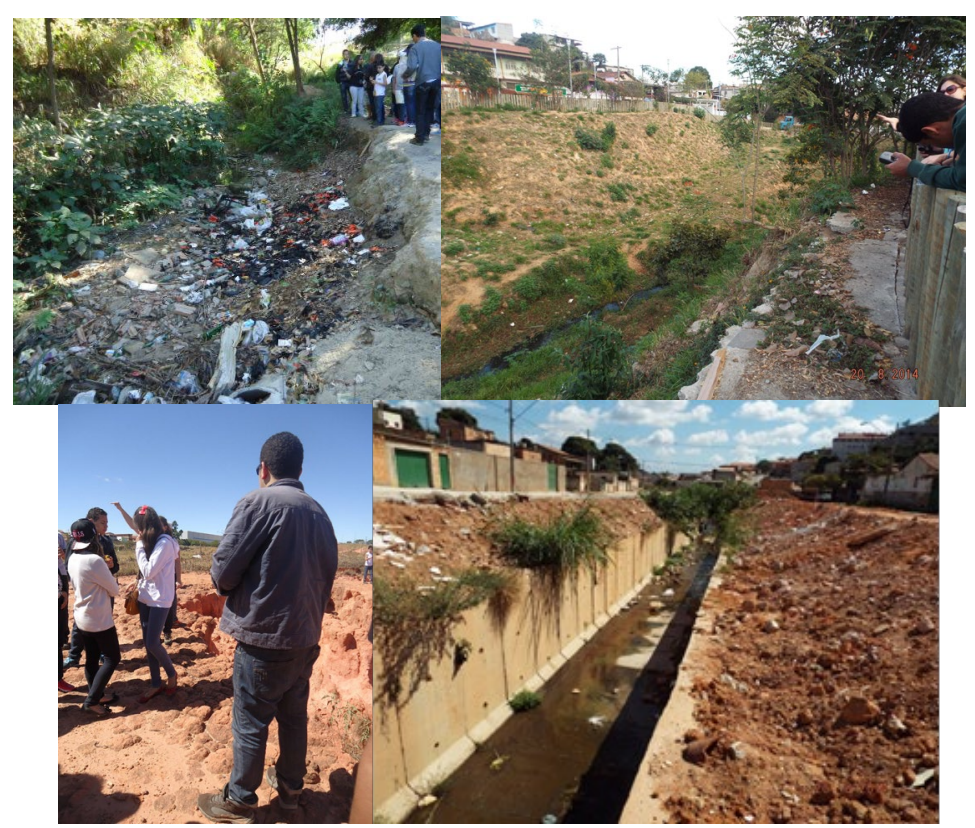

Figura 05: Trabalho de Campo na microbacia do córrego João Gomes Cardoso, Contagem-MG.

Fonte: Acervo do Projeto Mapeamento e Monitoramento, 2014, Proex UFMG.

\section{D - Oficinas de mapa metal e maquete da microbacia}

Foi elaborada uma maquete por escola, assim como realizada uma oficina por escola, totalizando, portanto, três maquetes e três oficinas. Nas oficinas de mapa mental propomos aos alunos que desenhassem e descrevessem o percurso de suas casas até a escola, mas que incluíssem o que achassem necessário para a identificação e localização do leitor. Pedimos que considerassem os (1P) problemas, as (2P) potencialidades e as (3P) possibilidades ambientais ao longo do caminho utilizando a metodologia $3 \mathrm{P}$.

Na sequência dos desenhos, as maquetes - que foram construídas na UFMG pelos bolsistas do projeto da microbacia do Córrego do João Gomes Cardoso na dimensão de $100 \mathrm{~cm}$ x $50 \mathrm{~cm}$ - eram expostas aos alunos. Para serem feitas sem a ajuda de outros, no livro Geotecnologias na Educação para Gestão das Águas: Mapeamento Geoparticipativo 3P (Gianasi \& Campolina, 2016), há um roteiro de orientação bem simples no intuito de auxiliar a qualquer público na confecção delas. 


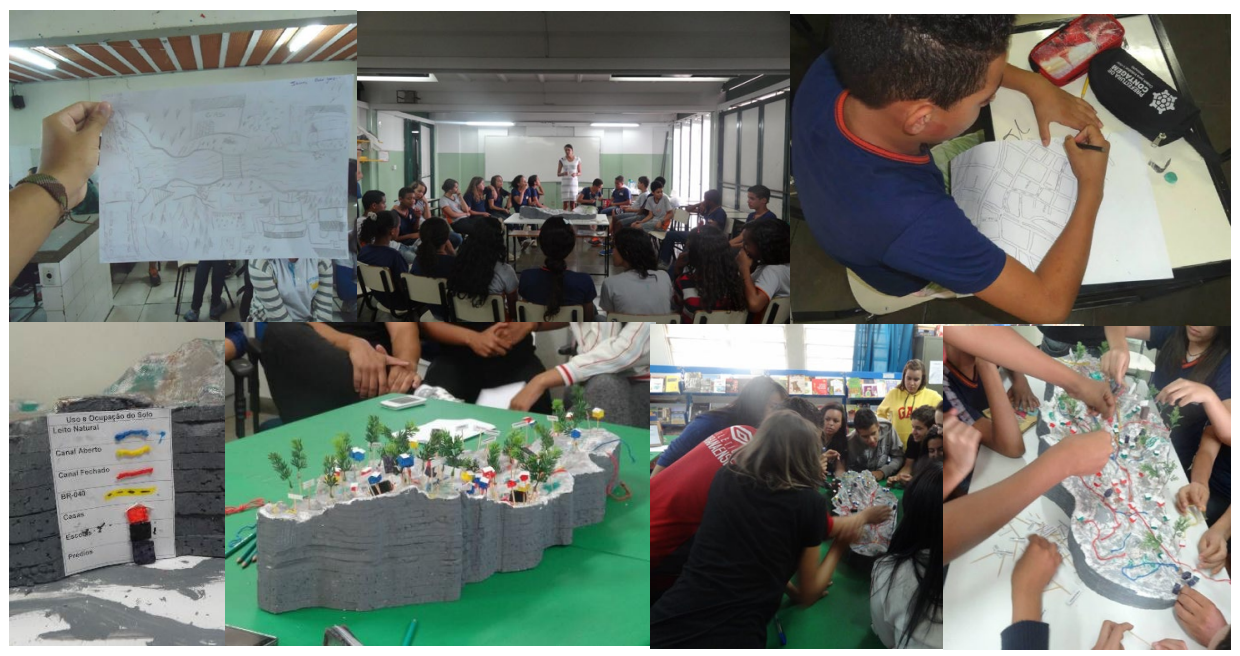

Figura 06: Oficina com a maquete da microbacia do córrego João Gomes Cardoso, ContagemMG.

Fonte: Acervo do Projeto Mapeamento e Monitoramento (2014), Proex UFMG.

A proposta era que os alunos tentassem localizar sua escola, suas casas e pontos significativos dentro da microbacia, bem como potencialidades e problemas ambientais dentro do território, parte do que havia sido trabalhado anteriormente no desenho do mapa mental e no campo. A espacialização dos itens levantados pelos alunos era inserido na microbacia com placas e ícones representativos.

\section{E - Oficinas Google Earth}

Em cada escola participante foi realizada uma oficina que se dividiu em duas etapas. Na primeira etapa ocorreu a apresentando o software Google Earth e suas respectivas ferramentas e possibilidades de utilização delas no mapeamento. Alguns participantes já conheciam o software e/ou já tiveram contato com o Google Maps que apesar de auxiliar também na localização não permite a marcação de pontos. Na segunda etapa da oficina os alunos foram agrupados segundo critério de proximidade da moradia. Cada grupo de alunos, com auxílio de notebooks levados pela equipe do Projeto, visualizou imagens das proximidades de suas casas e iniciou um mapeamento. Apesar de a maioria das escolas possuírem laboratórios de informática estes não estavam em funcionamento devido a algum problema técnico e/ou não possuíam internet. Por isso para viabilizar a oficina os bolsistas levaram notebooks de laboratório do IGC nos quais salvaram previamente as imagens de satélite com algumas marcações como, por exemplo, a localização das escolas e a delimitação da bacia hidrográfica, de forma que a segunda etapa da oficina ocorresse mesmo na ausência de laboratório de informática, assim como de internet. 


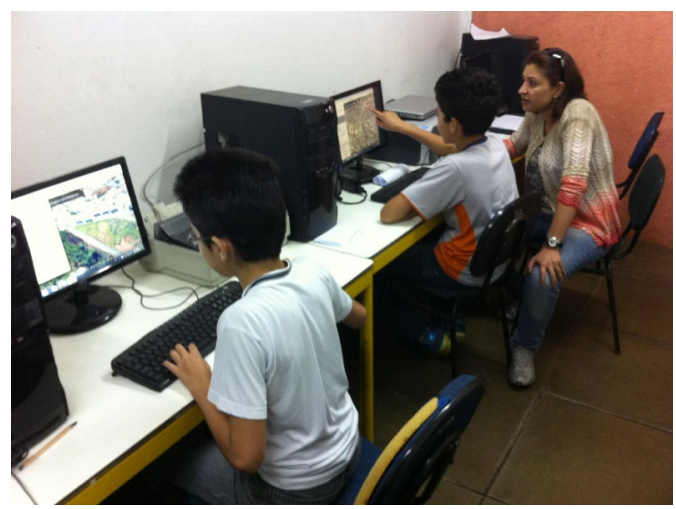

Figura 07: Oficina produção dos mapas digitais com o Google Earth da microbacia do córrego João Gomes Cardoso, Contagem-MG.

Fonte: Acervo do Projeto Mapeamento e Monitoramento (2014), Proex UFMG.

\section{F - Mapeamento pelos alunos}

Ao final das oficinas de Google Earth cada um dos participantes recebeu um $\mathrm{Cd}$ com as apresentações realizadas durante o projeto, com um tutorial de uso do Google Earth e imagens de satélite referentes a bacia, assim como arquivos de extensão KML de forma que pudessem ser abertos no Google Earth. Ficou acordado que cada grupo iria continuar o mapeamento tanto na identificação de (1P) problemas e $(2 \mathrm{P})$ potencialidades via Google Earth como indo ao campo e marcando posteriormente com as ferramentas do Google Earth o que tivesse sido mapeado. Os dados salvos em arquivos KML seriam recolhidos na escola pelos bolsistas do Projeto, em data previamente acordada entre estes e os alunos.

\section{Resultados e percepções}

A metodologia 3P é pertinente por estimular a subjetividade dos discentes, já que parte do processo de que é a ação do sujeito ao se reconhecer no território que o torna atuante. Segundo os alunos, essa educação vinda de instâncias fora da escola proporciona uma nova visão conjunta e participativa fazendo com que deixassem de jogar lixo próximo ao córrego, por exemplo. Os alunos acreditam que somente por meio de projetos como esse é que diversas pessoas seriam alertadas sobre a importância da conservação ambiental para os córregos.

$\mathrm{Na}$ oficina do mapa mental e maquete levamos uma representação tridimensional da microbacia, material pedagógico com grande potencial em trabalhos envolvendo reconhecimento territorial principalmente pelo fato dos limites da bacia não coincidirem com os limites políticos sendo, portanto, de difícil identificação não apenas pelos alunos, mas também pelos professores. Por meio da maquete foi possível identificar com os alunos e professores, através da própria dinâmica da oficina, os seus 
pensamentos sobre esse território e o meio ambiente. A maior parte dos alunos participantes do projeto mora dentro ou próximo dos limites da microbacia. Identificando na maquete pontos como nascentes, trechos do córrego que são canalizadas e outros poucos que ainda estão em leito natural os alunos perceberam e discutiram sobre a degradação ocorrida na bacia, segundo eles, principalmente nos últimos anos. Percebemos que a discussão se encaminhou para um viés contrário ao tecnicismo que insiste em canalizar rios. Os alunos defendiam diferentes possibilidades que não fosse a canalização como a criação de parques, ou seja, que o espaço fosse apropriado pela comunidade. Ao pedirmos que elencassem os problemas enxergados próximo às escolas foram listados violência, depredação e acúmulo de lixo em vários pontos como lotes vagos, passeio e até na entrada de uma das escolas. Por outro lado, também, foram identificados na maquete pontos com potenciais de recuperação e acima de tudo como pontos que merecem maior valorização pela comunidade e por órgãos públicos.

Na oficina sobre Google Earth percebemos que o software proporcionou novas formas de enxergar o espaço, o que pode implicar em novas formas de pensar o território e poder agir e reagir sobre a temática de rios e seus problemas e soluções. Pelas imagens de satélite os alunos identificaram suas escolas, suas casas e também indicaram pontos sinalizando (1P) problemas, (2P) potencialidades e (3P) possibilidades para a microbacia. Houve participação de professores de áreas diversas das escolas como: Matemática, Ensino Religioso, Geografia, História e Pedagogia.

Apesar de vários apontamentos das dificuldades que serão esboçadas mais especificamente no próximo item, a metodologia 3P, o trabalho de campo as oficinas conseguiram estimular novas leituras do território vivido pelos alunos. A indicação pelos alunos dos 3Ps nas áreas estudadas sinaliza os diferentes olhares sob o território da bacia, proporcionado pelo mapeamento. Pôde ser trabalhada também a metamorfose da paisagem principalmente tendo como base os resultados dos projetos anteriores e a série histórica de imagens de satélite do local estudado através do Google Earth. Alguns conceitos geográficos foram bem assimilados, isso facilitou o desenvolvimento das oficinas, apesar das dificuldades de entendimento de conceitos cartográficos. $\mathrm{O}$ trabalho de campo proporcionou aos alunos novas visões sobre lugares que já conheciam permitindo que olhassem para os processos de degradação ambiental que ocorrem em áreas próximas de suas casas e escolas de forma mais crítica.

As oficinas tiveram como objetivo principal mostrar aos alunos a produçãoreprodução do espaço, apresentando ferramentas para que eles próprios sejam capazes não somente de serem reprodutores de diversos discursos, mas que possam criar novos discursos sobre o urbano e o ambiental.

\section{Reflexões e apontamentos: muitos desafios}

As reflexões apontam tanto resultados positivos do ponto de vista pedagógico, imaginados e não programados para o projeto, quanto do ponto de vista político, pensados quando delineamos e desenvolvemos a proposta. Esses resultados estão atrelados a uma diversidade de fatores que nem sempre são previstos - pois são 
dinâmicos e não estáticos - durante o momento de elaboração dos programas e projetos dinâmica da escola, interesse dos professores, comprometimento e envolvimento da escola, materiais e processos de sensibilização. Com intuito de traçar reflexões que possam auxiliar propostas futuras de mapeamento geoparticipativo como o apresentado no presente relato, ou mesmo propostas de outros teores, mas que envolvam escolas e projetos de extensão, reunimos em cinco grupos os fatores que interferiram no desenvolvimento do projeto relatado:

\section{$>$ O tempo para a formação e a execução das atividades propostas}

Apesar de previstas mais horas de formação para os alunos e professores no projeto original, não foi possível cumpri-las devido a indisponibilidade das escolas. Em projetos anteriores a formação (oficinas, palestras e trabalhos de campo) era realizada com professores e estes estavam à frente da realização de atividades junto aos alunos. Mas, no projeto relatado não foi possível manter o formato de formação dos professores, pois a escola não liberava o professor em seu horário de trabalho para a realização das atividades de formação, assim como estes não se disponibilizavam a fazer a formação no final de semana, pois era o pouco tempo que tinham para realizar atividades de cunho pessoal. Concluímos que no caso específico das escolas envolvidas não há um desejo e colaboração da administração escolar em investir no processo contínuo de formação - algo que também pode estar associado não apenas a administração escolar, mas também ao sistema municipal e estadual de educação. Uma das possibilidades poderia ser a realização de parcerias mais coesas entre as Secretarias Municipal e Estadual de Educação e a universidade já que ser trata de um projeto de extensão. Outra possibilidade é verificar a possibilidade de implantar propostas como o aqui relatado em escolas integrais, ou seja, de maneira que as atividades formativas e mesmo o mapeamento pudessem ocorrer no contraturno de aula o que permitiria maior disponibilidade de tempo além de maior flexibilidade de ações.

\section{$>$ A dinâmica rígida de funcionamento das escolas}

A dinâmica rígida de funcionamento das escolas dificulta o desenvolvimento de projetos como o relatado. A dificuldade em realizar os trabalhos de campo com os alunos, e principalmente da própria escola enviar sempre a mesma turma e mesmo professor para as atividades foi outro fator dificultador. Mesmo diminuído o número de encontros com alunos e professores em relação a proposta inicial, com intuito de adequar a realidade das escolas, a direção entendia que a mesma turma perderia muitas aulas da mesma forma que o mesmo professor ficaria muito tempo fora de sala, para a realização das atividades propostas. É preciso que a administração escolar também reconheça em propostas como a do projeto relatado como uma possibilidade de formação e não apenas de atividades executadas e desarticuladas. Por mais que o professor tenha interesse em participar, ele se vê preso a uma estrutura rígida de administração escolar que nem sempre valoriza e reconhece a importância de 
projetos de extensão. A nosso ver essas percepções remetem à concepção de uma escola na qual não é concebida a troca de saberes, o que Paulo Freire (1996) designava de educação bancária, na qual o aluno é visto uma tábua lisa na qual se adiciona, deposita conhecimentos.

\section{$>$ Infraestrutura limitada das escolas}

O uso imagens de satélite e de ferramentas do Google Earth apesar de terem grande potencial pedagógico podem comprometer o desenvolvimento do projeto quando este envolve escolas públicas. Há casos de insistência de laboratórios de informática, mas muitas escolas possuem os laboratórios, mas estes não funcionam, ou por questões estruturais, ou por falta de manutenção dos computadores. Laboratórios funcionando, com profissionais específicos (monitores, técnicos em informática) e com acesso a internet é ainda mais difícil. Essa realidade é extremamente limitante para propostas como a de mapeamento geoparticipativo. A equipe tentou sanar essas dificuldades levando alguns notebooks já com as imagens salvas de maneira que pudessem acessá-las pelo Google Earth mesmo sem a presença de internet, o que comprometeu o rendimento da oficina não apenas pelo número pequeno de notebooks em relação ao de alunos, mas também pela baixa qualidade das imagens sem o acesso à internet.

\section{$>$ Defasagem de Conhecimentos Geográficos}

O projeto foi elaborado para um público de alunos do qual se esperava que já tivessem uma bagagem de conhecimentos geográficos como noções de orientação e espacialidade. Mas, durante as oficinas notamos que foi preciso retomar vários outros conceitos geográficos para que os alunos tivessem maior consciência e percepção geoespacial durante o desenvolvimento das atividades. Projetos como esse demandam de um tempo maior de formação - como já citado em itens anteriores - para o nivelamento de conhecimentos geográficos, especialmente cartográficos dos alunos e até mesmo dos professores, considerando que nem todos os participantes têm formação em Geografia. Há também uma falta de conhecimentos cartográficos envolvendo a bacia na qual esses professores atuam, portanto, mesmo que o projeto envolva apenas professores de Geografia provavelmente eles não terão conhecimento da dinâmica da bacia na qual a escola que atua se localiza. E mesmo que estes professores acompanhem por um ano o mapeamento da área e tenham acesso a um banco de dados sobre a bacia, devido a grande complexidade desta, um ano de dados pode ainda não contemplar toda a diversidade e dinâmica da microbacia. Em temos de temática tratada, entender o território de bacia - é ainda uma grande dificuldade, e acaba-se gastando tempo com um nivelamento de conhecimento para a progressão de uma discussão a realizada para o desenvolvimento do método $3 \mathrm{P}$. 


\section{$>$ Defasagem de Conhecimentos Tecnológicos}

Apesar do acesso cada vez maior às novas tecnologias, muitos professores e alunos não conheciam o software Google Earth. Trabalhar com grupos heterogêneos no que se refere à níveis distintos de conhecimentos tecnológicos aplicados ao ensino de Geografia é um grande desafio. Geógrafos licenciados que já atuam há muito tempo na educação não tinham conhecimento e muito menos utilizaram ferramentas como o Google Earth e outras como o GPS, até mesmo de celular, como potencial pedagógico. Isso torna a abordagem mais difícil, necessitando de mais tempo para o nivelamento de informações, assim como para apresentação de novas tecnologias e o uso delas como potencial pedagógico.

\section{Considerações finais}

A experiência relatada apresenta-se como grande potencial pedagógico na área de ensino em Geografia, podendo não apenas auxiliar no entendimento da espacialidade e da dinâmica do território de bacia hidrográfica, mas auxiliar na construção de uma visão crítica sobre as transformações ocorrentes e como elas influenciam na quantidade e qualidade de água.

Investir em novos métodos de ensino aprendizagem como os aqui apresentados pode proporcionar melhor desempenho no desenvolvimento dos estudantes, principalmente se esses tratarem de tecnologias que podem ser utilizadas no entendimento dos fenômenos de processos espaciais como as geotecnologias, mas dificuldades no acesso das geotecnologias podem ser encontradas pelos professores. Projetos como esse têm o intuito de quebrar certos estigmas e diminuir o distanciamento de novas abordagens no ensino-aprendizagem dos alunos na educação básica e mostrar aos professores possibilidades metodológicas, além de disseminar conteúdos estritamente trabalhados nas universidades. Acreditamos que este tipo de abordagem pode despertar o interesse dos participantes para que busquem e exijam outros meios de produção do espaço.

A proposta de mapeamento geoparticipativo 3P, além de possibilitar reflexões e novas leituras sobre o território das águas, pode produzir banco de dados minuciosos sobre microbacias, o que não existe de maneira sistematizada no Brasil. Apesar de um Sistema Nacional de Informações sobre Recursos Hídricos vinculado ao Sistema Nacional de Recursos Hídricos estar em implantação, ele está longe de contemplar territórios menores como microbacias. As informações levantadas pelos alunos se sistematizadas e organizadas podem também contribuir para a gestão do território, podendo ser compartilhada com o subcomitê e o Comitê de Bacia Hidrográfica responsável legalmente pela gestão desse território. Mas, infelizmente diante dos desafios relatados não se conseguiu formar um extenso banco de dados sobre a microbacia do córrego João Gomes Cardoso, o que não impede que outros esforços sejam realizados, via projetos de extensão ou mesmo projetos vinculados a prefeituras, ao estado e aos CBHs. Com um banco de dados criados e alimentado pela própria 
população via educação escolar é possível se pensar em um futuro monitoramento da área e a cobrança de mudanças.

A educação geográfica junto com o uso de geotecnologias em um processo contínuo de formação, diálogo e construção conjunta de saberes (escola-comunidadeuniversidade) apresenta-se como detentora de grande potencial não apenas formador, mas, sobretudo transformador. Mas, é essencial reconhecer os desafios enfrentados em projetos como esse, para que a educação geográfica vá além do (re)conhecer o território dinâmico das bacias, mas também de desenvolver ações que possam fortalecer a construção de uma gestão realmente participativa das águas.

\section{Referências}

ABERS, R. Introdução: pensando politicamente a gestão da água. In: ABERS, Rebecca (org). Água e política: atores, instituições e poder nos Organismos Colegiados de Bacia Hidrográfica no Brasil. São Paulo: Annablume, 2010.

ACSELRAD, H. (org). Cartografia social e dinâmicas territoriais: marcos para o debate. Rio de Janeiro: Universidade Federal do Rio de Janeiro, Instituto de Pesquisa e Planejamento Urbano e Regional, 2010.

BRASIL. Congresso Nacional. Lei Federal 9.433, de 08 de janeiro de 1997. Institui a Política Nacional de Recursos Hídricos. Brasília, 1997. BRASIL, 1997.

BRASIL. Ministério do Meio Ambiente, Secretaria de Recursos Hídricos e Ambiente Urbano. PAULA JÚNIOR, F. de.; MODAELLI, S. (Org.). Política de águas e educação ambiental: processos dialógicos e formativos em planejamento e gestão de recursos hídricos. Brasília: MMA/SRHU, 2013. 288 p.

BRASIL, Secretaria de Educação Fundamental. Parâmetros Curriculares Nacionais Terceiro e quarto ciclos: Geografia. Brasília: MEC/SEF, 1998.

CALLAI, H. C. Estudar o lugar para compreender o mundo. In: CASTROGIOVANI, Antônio C. (org.). Ensino de Geografia: práticas e contextualizações. Porto Alegre: Mediação, 2000.

CAMPOLINA, D. Educação Ambiental na estruturação de Mundos Possíveis: o caso do Núcleo João Gomes Cardoso - MG. 2014. 240f. Dissertação (Mestrado em Educação) Programa de Pós-graduação Conhecimento e Inclusão Social da Faculdade de Educação, Universidade Federal de Minas Gerais, Belo Horizonte, 2014.

CAMPOLINA, D; GIANASI, L. Mapeamento Geoparticipativo 3P: informação, formação e empoderamento. In: M; Claudino, S.; Souto González, X.; Rodriguez Domenech, M.; Bazolli, J.; Lenilde de Araújo, R.; Gengnagel, C.; Mendes, L.; Silva, A. (org.) (2019). Geografia, Educação e Cidadania. Lisboa: ZOE/Centro de Estudos Geográficos, Instituto de Geografia e Ordenamento do Território da Universidade de Lisboa. 959p. 
CARMO, A. M. R.; CAMPOLINA VIEIRA, D. Mapeamento Participativo em Territórios de Bacias Hidrográficas: um agir coletivo. Revista Geonorte, v. 4, p. Revista Geonorte, 2012.

CASTELLAR. S. M. V. Educação Geográfica: teorias e práticas docentes. Campinas: Contexto, 2005.

CAVALCANTI, L. de S. Bases teórico-metodológicas da Geografia: uma referência para formação e a prática de ensino. In: CAVALCANTI, Lana de Souza. (org.). Formação de professores: concepções e práticas em Geografia. Goiânia: Vieira, 2006.

CAVALCANTI, L. de S. Geografia e práticas de ensino. Goiânia: Alternativa, 2002.

CAVALCANTI, L. de S. Geografia, escola e construção de conhecimentos. CampinasSP: Papirus, 1998.

CLAUDINO, S. (2014). Escola, educação geográfica e cidadania territorial. Revista Electrónica de Geografía y Ciencias sociales, Barcelona, v. 18, n. 496, p. 1-10. 2014.

FREIRE, P. Pedagogia da autonomia: saberes necessários à prática educativa. São Paulo: Paz e Terra, 1996.

GIANASI, L. M.; CAMPOLINA, D. Geotecnologias na educação para gestão das águas: mapeamento geoparticipativo 3P. 1. ed. Belo Horizonte: Fino Traço, 2016. v. 1. $104 \mathrm{p}$.

GIANASI, L. M.; VIEIRA, D. C.; PIMENTA, R. H. Mapeamento geo-participativo: saberes científicos e populares na estruturação de uma gestão participativa das águas. In: XXVI CBC; V Congresso Brasileiro de Geoprocessamento e XXV Exposicarta, 2014, Gramado. XXVI Congresso Brasileiro de Cartografia; V Congresso Brasileiro de Geoprocessamento e XXV Exposicarta, Anais 2014.

JÚNIOR, W. C. de S; FIDELMAN, P. I. Ja. A Tecnopolítica da água no Brasil. In: RIBEIRO, W. C. (org.). Governança da água no Brasil: uma visão interdisciplinar. São Paulo: Annablume; Fapesp; CNPq, 2009.

KAERCHER, N. PCNs: Futebolistas e padres se encontram num Brasil que não conhecemos. Terra Livre - Dossiê: Os PCNs em discussão, n 13, ago, 1997.

LEMOS, M. C., et al. Informação técnica e gestão participativa de bacias hidrográficas no Brasil. In: ABERS, Rebecca (org). Água e política: atores, instituições e poder nos Organismos Colegiados de Bacia Hidrográfica no Brasil. São Paulo: Annablume, 2010.

MACHADO, A. T. G. M.; et al. Bacia hidrográfica como instrumento para a transversalidade. 1. ed. Belo Horizonte: Instituto Guaicuy, 2011. v. 1000. 96 p.

REBOUÇAS, A.C.; BRAGA, B.; TUNDISI, J. G. Águas doces do Brasil: capital ecológico, uso e conservação. 2. ed. Escrituras, Editora e Distribuidora de Livros Ltda., 2001. 
RIBEIRO, W. C. (org.). Governança da água no Brasil: uma visão interdisciplinar. São Paulo: Annablume; Fapesp; CNPq, 2009.

SOUZA, V. C. Fundamentos Teóricos, Epistemológicos e Didáticos no Ensino da Geografia: bases para formação do pensamento espacial crítico. Revista Brasileira de Educação em Geografia, Rio de Janeiro, v. 1, n. 1, p. 47-67, jan./jun., 2011.

STRAFORINI, R. Ensinar Geografia: um desafio da totalidade-mundo nas séries iniciais. São Paulo: Annablume, 2004.

VIEIRA, D. C. et al. Mapeamento Participativo: ferramenta de mobilização e incentivo à autonomia. Anais VII Fórum Brasileiro de Educação Ambiental. Salvador, 2012.

VIEIRA, D. C; GIANASI, Lussandra M.; PINHEIRO, T. M. M. Gestão das Águas no Brasil: vamos participar? Mapeamento geoparticipativo, participação social e gestão das águas na bacia hidrográfica do ribeirão Onça do estado de Minas Gerais. Instituto Guaicuy. Belo Horizonte, 2013. p. 40.

VIEIRA, D. Ca; GIANASI, L. M. et al. Roteiro de Mapeamento participativo para professores. In: MACHADO, A. T. G. M. et al. Bacia Hidrográfica como instrumento pedagógico para a transversalidade. Belo Horizonte: Projeto Manuelzão - UFMG/ Instituto Guaicuy - SOS Rio das Velhas, p.85-92, 2011.

\footnotetext{
Agradecemos ao Laboratório de Geografia Agrária, Agricultura Familiar e Cultura Camponesa do IGC-UFMG onde parte dos trabalhos foram realizados e ao Projeto Manuelzão-UFMG, base para o aperfeiçoamento em extensão das autoras. Louvamos a FAPEMIG pelo financiamento do projeto "Capacitação de professores, produção e divulgação de conhecimentos sobre microbacias urbanas da bacia do rio das Velhas como instrumento de gestão participativa do ambiente" (2011-2013) ao Programa Proext 2010, edital 5 "Ambiente, educação, saúde e cidadania para as microbacias urbanas e bacias do rio das Velhas" (2011-2012) e ao Financiamento pelo edital PROEXT-MEC SESu 2014 e realizado de janeiro de 2014 a julho de 2015. Dizer que o financiamento é FUNDAMETAL para a realização de pesquisas e de extensão nas universidades públicas e de qualidade do Brasil foi um orgulho, espero que volte a ter a mesma ponderação no futuro.
}

\footnotetext{
Lussandra Martins Gianasi

É geógrafa, doutora em Geografia e professora da UFMG do departamento de Geografia. Atualmente coordena e é pesquisadora do Laboratório de Geografia Agrária, Agricultura Familiar e Cultura Camponesa do IGC-UFMG. É líder do Núcleo de Pesquisas TERRA \& SOCIEDADE do CNPQ (dgp.cnpq.br/dgp/espelhogrupo/6449472643744059). Endereço: Universidade Federal de Minas Gerais, Av. Antônio Carlos, 6627 - Pampulha, Belo Horizonte MG, CEP 31270-901.

Email: lussandrams@gmail.com
} 


\section{Daniela Campolina Vieira}

É Bióloga, doutoranda em educação pela UFMG na FAE. Endereço: Universidade Federal de Minas Gerais, Av. Antônio Carlos, 6627 - Pampulha, Belo Horizonte MG, CEP 31270-90. É educadora e mobilizadora integrante do Movimento pelas Serras e Águas de Minas (MovSAM) http://movsam.ning.com/.

Email: danicampolina@gmail.com

Recebido para publicação em dezembro de 2018 Aprovado para publicação em outubro de 2019 